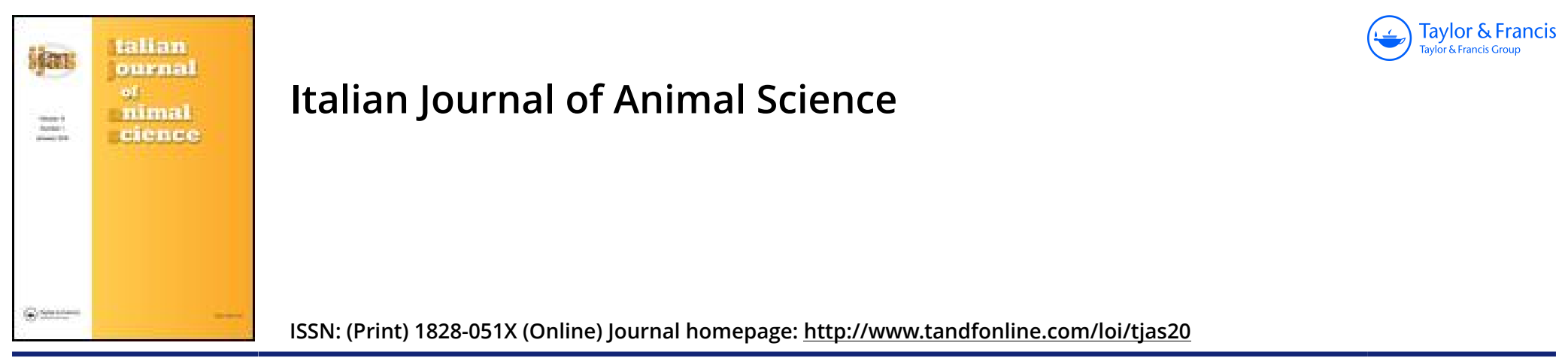

\title{
Characterization and kinetics studies of water buffalo (Bubalus bubalis) myoglobin
}

\section{R. Dosi, Di Maro, A. Chambery, G. Colonna, S. Costantini, G. Geraci \& A. Parente}

To cite this article: R. Dosi, Di Maro, A. Chambery, G. Colonna, S. Costantini, G. Geraci \& A. Parente (2007) Characterization and kinetics studies of water buffalo (Bubalus bubalis) myoglobin, Italian Journal of Animal Science, 6:sup2, 1210-1213, DOI: 10.4081/ijas.2007.s2.1210

To link to this article: http://dx.doi.org/10.4081/ijas.2007.s2.1210

$$
\text { C) Copyright } 2007 \text { Taylor and Francis Group }
$$

曲 Published online: 15 Mar 2016.

Submit your article to this journal $\pi$

山 Article views: 9 


\title{
Characterization and kinetics studies of water buffalo (Bubalus bubalis) myoglobin
}

\author{
R. Dosi ${ }^{1}$, A. Di Maro ${ }^{1}$, A. Chambery ${ }^{1}$, G. Colonna ${ }^{2}$, \\ S. Costantini ${ }^{3}$, G. Geraci ${ }^{4}$, A. Parente ${ }^{1}$ \\ 1 Laboratorio Integrato per la Qualità e la Sicurezza degli Alimenti, \\ CRdC "Produzioni Agroalimentari", Second University of Naples, Caserta, Italy \\ 2 Department of Biochemistry and Biophysics and CRISCEB, \\ Second University of Naples, Naples, Italy \\ ${ }^{3}$ Institute of Food Science, CNR, Avellino, Italy \\ 4 Department of Biological Sciences, Via Mezzocannone 8, University of Naples Federico II, Italy \\ Corresponding author: A. Parente, Laboratorio Integrato per la Qualità e la Sicurezza degli Alimenti, \\ CRdC "Produzioni Agroalimentari", Second University of Naples, Via Vivaldi 43, I-81100 Caserta, Italy \\ - Tel. +39 0823274583 - Fax: +39 0823274571 - Email: augusto.parente@unina2.it
}

\begin{abstract}
It is generally accepted that dry-aged buffalo (B. bubalis) meat becomes dark faster than bovine (B. taurus) meat, discouraging consumer purchase. We have investigated whether this faster darkening process might depend on structural and/or kinetic differences between buffalo and bovine myoglobins (Mbs). To this end, we have purified to homogeneity buffalo $\mathrm{Mb}$ from Longissimus dorsi muscle and obtained both its $\mathrm{Mr}(17,034.5)$ and the complete amino acid sequence, which, compared with the bovine one, showed three amino acid substitutions: $\mathrm{D}_{\mathrm{bo}} 141 \mathrm{E}_{\mathrm{bu}}, \mathrm{A}_{\mathrm{bo}} 19 \mathrm{~T}_{\mathrm{bu}}$ and $\mathrm{A}_{\mathrm{bo}} 117 \mathrm{D}_{\mathrm{bu}}$. As revealed by the 3D structure, they were located on the surface of the protein, far from the heme binding pocket, and did not cause appreciable structural changes. Autoxidation rates of purified buffalo and bovine myoglobins at $37^{\circ} \mathrm{C}, \mathrm{pH} 7.2$, were almost identical $\left(0.052 \pm 0.001 \mathrm{~h}^{-1}\right.$ and $0.054 \pm 0.002 \mathrm{~h}^{-1}$, respectively), as were their oxygen-binding $\mathrm{Kd}$ values $(3.7 \pm 0.1 \mu \mathrm{M}$ and $3.5 \pm 0.1 \mu \mathrm{M}$, respectively). These data indicate that the structure of the heme pockets in the two proteins is similar, with similar functional properties. Moreover, the percent of MetMb values in the purified buffalo and bovine samples, after the same time from slaughtering, were almost identical (57\% and $47 \%$, respectively). The results presented here suggest that the faster darkening of buffalo meat depends on factors other than the oxidation rate of its $\mathrm{Mb}$, as, for example, the Mb content $(0.393 \pm 0.005$ $\mathrm{g} / 100 \mathrm{~g}$ ) and consequently its MetMb content, which is almost twice as high as bovine meat $(0.209 \pm 0.003 \mathrm{~g} / 100 \mathrm{~g})$, and likely other factors.
\end{abstract}

INTRODUCTION - Myoglobin (Mb) is the most important determinant for meat colour. In living animals, there is an equilibrium between the purplish-red $\mathrm{Mb}$ form (deoxyMb) and the cherry-red form (oxyMb or $\mathrm{MbO}_{2}$ ). During meat storage, these two reduced $\mathrm{Mb}$ forms readily become oxidized to the brownish-red metMb (Faustman et al., 1990). Over the last 20 years it has been shown that there is up to a 12 -fold difference in the rate at which $\mathrm{Mb}$ oxidizes in post-mortem mammalian muscles, depending on the species and muscle 
type (Livingston et al., 1986; Foucat et al., 1994; Tada et al., 1998; Stewart et al., 2004). Recently, water buffalo meat, derived from male animals, is being introduced in the fresh meat market of Southern Italy, as an alternative to the bovine one. Compared to the latter, water buffalo meat is presented as having higher nutritional properties, although there are conflicting reports (Syed Ziauddin et al., 1993; Cutrignelli, 1996; Infascelli et al., 2004; Spanghero et al., 2004). The aim of this study is to investigate whether the reasons for the faster darkening process of buffalo meat might depend on structural differences between buffalo and bovine Mbs. Therefore, we have: i) purified buffalo $\mathrm{Mb}$; ii) determined its average amount in meat; iii) determined its primary structure and main structural properties, and iv) studied Kd values and autoxidation kinetics to establish the possible occurrence of correlation with the amino acid substitutions.

MATERIAL AND METHODS - Myoglobin was purified from the Italian water buffalo (Bubalus bubalis) skeletal muscle (Longissimus dorsi), provided by "Cooperativa La Baronia", Pontelatone, Caserta (Italy). Buffalo $\mathrm{Mb}$ was purified using the following procedure: i) homogenization; ii) dialysis against MilliQ water; iii) gel-filtration on a Sephacryl S-100 column and, iv) anion-exchange chromatography on a DEAE-Sepharose column. Mb concentration was determined at the isosbestic point of $527 \mathrm{~nm}$ using a $\mathrm{E}_{1 \%, 1 \mathrm{~cm}}$ coefficient of 2.7. Determination of percent values of MetMb in the purified preparations of buffalo and bovine samples, collected after the same time from slaughtering, were performed spectroscopically according to Krzywicki (1982). The autoxidation of $\mathrm{MbO}_{2}$ to metMb was monitored by recording, over time, the changes of the absorption spectrum in the range 500-700 $\mathrm{nm}$ at measured time intervals, and estimating the absorbance decrease at $582 \mathrm{~nm} . \mathrm{MbO}_{2}$ was prepared by sodium dithionite reduction of pure $\mathrm{Mb}$. The relative molecular mass of buffalo apo-Mb, obtained from RP-HPLC in the presence of $0.1 \%$ TFA, was determined using a Q-TOF Micro mass spectrometer, equipped with a CapLC system. The acquisition and deconvolution of data were performed on a Mass Lynx Windows NT PC data system. Automated Edman degradation was performed on the first 41 amino acid residues of the HPLC purified buffalo apoMb. Buffalo and bovine apo-Mbs were digested with trypsin, Glu$\mathrm{C}$ and cyanogen bromide (CNBr). Peptides masses were determined by MALDI-TOF mass spectrometry. Signals recorded in the mass spectra were associated with the corresponding peptides on the basis of the expected molecular mass calculated by using a suitable computer program (Peptide Tools, Hewlett-Packard). When necessary, Edman degradation steps were performed on the HPLC purified peptides, in order to confirm the assignment. The three-dimensional models of bovine and buffalo myoglobins were created by homology modelling, using the MODELER/QUANTA software.

RESULTS AND CONCLUSIONS - The purification procedure described in Materials and methods yielded reproducibly purified preparations of Mbs from the skeletal muscle of both water buffalo and bovine. The amount of $\mathrm{Mb}$ in samples from both animal sources was $0.393 \pm 0.005 \mathrm{~g} / 100 \mathrm{~g}$ of tissue for buffalo and $0.209 \pm 0.003 \mathrm{~g} / 100 \mathrm{~g}$ of tissue for bovine. Percent MetMb values in the purified buffalo and bovine samples, after the same time from slaughtering, were $57 \%$ and $47 \%$, respectively. The combined use of mass spectrometry and automated Edman degradation for the analysis of peptides obtained from trypsin, Glu-C and $\mathrm{CNBr}$ digestions, allowed us to obtain the entire sequence of $\mathrm{B}$. bubalis 
myoglobin. Further, the agreement between the experimental mass of the native protein $(17,034.5 \mathrm{Da})$ and that calculated on the basis of the amino acid sequence $(17,034.46 \mathrm{Da})$ is a further confirmation of the correctness of the analysis. The amino acid sequence of buffalo $\mathrm{Mb}$, compared with the bovine one, shows three amino acid substitutions (1.96\%) out of 153 amino acid residues, one of which is conservative $\mathrm{D}_{\text {bov }} 141 \mathrm{E}_{\text {buf }}$ and two non-conservative, $A_{\text {bov }} 19 \mathrm{~T}_{\text {buf }}$ and $\mathrm{A}_{\text {bov }} 117 \mathrm{D}_{\text {buf }}$ (Fig. 1). The three-dimensional structures of bovine and buffalo Mbs, obtained by homology modelling, are very much alike and, also, the $\mathrm{Mb}$ amino acids at the interface with the heme are well conserved in both organisms. The three amino acid substitutions between buffalo and bovine Mbs are located on the surface of the protein and far from the heme binding pocket and do not cause appreciable structural changes. It appears unlikely that they may be responsible of changes in molecular properties. Nevertheless, helices $\mathrm{A}$ and $\mathrm{G}$ in buffalo $\mathrm{Mb}$ are more destabilized. This last result may be explained considering that, in buffalo, helix $\mathrm{A}$, in position 19, has a threonyl amino acid residue, that is a destabilizing $\beta$-branched residue $\left(\mathrm{A}_{\text {bov }} 19 \mathrm{~T}_{\text {buf }}\right)$. In fact, it is known that an overall greater stability of helices in proteins is related to a combination of stabilizing factors, the most common being the low content of $\beta$-branched residues. Moreover, the presence of a negatively charged residue $\left(\mathrm{A}_{\text {bov }} 117 \mathrm{D}_{\text {buf }}\right)$ at the C-terminus of helix $\mathrm{G}$, certainly induces a destabilization of the helix dipole (Richardson et al., 1988). Buffalo and bovine $\mathrm{MbO}$, at $\mathrm{pH} 7.2$ and $37^{\circ} \mathrm{C}$, are equally resistant to autoxidation, with Kd values of $0.052 \pm 0.001 \mathrm{~h}^{-1}$ and $0.054 \pm 0.002 \mathrm{~h}^{-1}$, respectively. The $\mathrm{O}_{2}$ dissociation curves of purified bovine and buffalo $\mathrm{Mbs}$, in identical experimental conditions at $\mathrm{pH} 7.2$, were almost superimposable, providing similar $\mathrm{Kd}$ values $(3.7 \pm 0.1 \mu \mathrm{M}$ and $3.5 \pm 0.1 \mu \mathrm{M}$, respectively). These observations indicate that the similar structural architecture of the two proteins heme pockets involve similar functional properties. Therefore, Mb autoxidation rate does not influence buffalo meat colour (Dosi et al., 2006). This might depend on the higher $\mathrm{Mb}$ content found, likely together with other factors (Faustman et al., 1990).

Figure 1. Amino acid sequence of Bubalus bubalis $\mathrm{Mb}$, including the peptides obtained by treatment of $\mathrm{Mb}$ with trypsin, Glu-C endoproteinase and cyanogen bromide, compared to Bos taurus Mb. Substitutions are underlined.

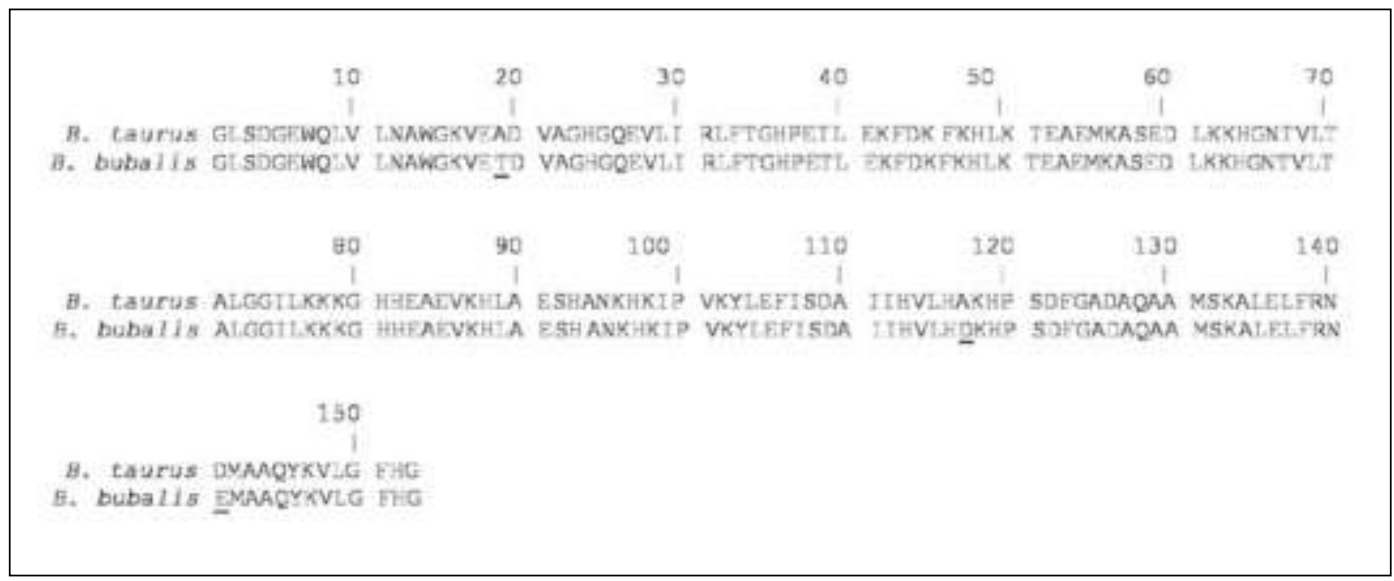


ACKNOWLEDGMENTS - This work was supported by Regione Campania, Italy (Centro Regionale di Competenza "Produzioni Agroalimentari", in the framework of the Project line C: "Carne di bufalo" (P.O.R. 2000-2006, Misura 3.16)) and by funds from the Second University of Naples. We thank Dr. Angelo M. Facchiano of Istituto di Scienze dell'Alimentazione, CNR, Avellino (Italy), for useful suggestions on computational analysis. R. Dosi thanks the Camera di Commercio of Caserta (Italy) for a fellowship.

REFERENCES - Cutrignelli, M.I., Calabrò , S., Laudadio, P., Grasso F., Di Lella, T., 1996. Chemical-nutritional characteristics of meat produced by young buffalo bulls. Proceeding of the XXXI International Symposium of Zoothecny "Role of animal products on animal health", Milan, Italy, pp. 101-106. Dosi, R., Di Maro, A., Chambery, A., Colonna, G., Costantini, S., Geraci, G., Parente, A, 2006. Characterization and kinetics studies of water buffalo (Bubalus bubalis) myoglobin. Comparative Biochemistry and Physiology, Part B. 145:230-238. Faustman, C., Cassens, R.G., 1990. The biochemical basis for discoloration in fresh meat: a review. J. Muscle Foods. 1:217-243. Foucat, L., Renerre, M., Gatellier, P., Anton, M., 1994. 1H NMR study of bovine myoglobin autoxidation. Influence of muscle type and time post-mortem. Int. J. Food Sci. Technol. 29:1-8. Gross, E., 1967. The cyanogen bromide reaction. Methods Enzymol. 11:238-257. Infascelli, F., Gigli, S., Campanile, G., 2004. Buffalo meat production: performance infra vitam and quality of meat. Vet. Res. Commun. 1(28):143-148. Krzywicki, K., 1982. The determination of haem pigments in meat. Meat Science. 7:29-36. Livingston, D.J., Watts, D.A., Brown, W.D., 1986. Myoglobin interspecies structural differences. Effects on autoxidation and oxygenation. Arch. Biochem. Biophys. 249:106-115. Richardson, J.S., Richardson, D.C., 1988. Amino acid preferences for specific locations at the ends of alpha helices. Science. 240:1648-1652. Stewart, J.M., Blakely, J.A., Karpowicz, P.A., Kalanxhi, E., Thatcher, B.J., Martin, B.M., 2004. Unusually weak oxygen binding, physical properties, partial sequence, autoxidation rate and a potential phosphorylation site of beluga whale (Delphinapterus leucas) myoglobin. Comp. Biochem. Physiol. B. 137:401-412. Syed Ziauddin, K., Mahendrakar, N.S., Rao, D.N., Ramesh, B.S., Amla, B.L., 1993. Observations on some chemical and physical characteristics of buffalo meat. Meat Sci. 37:103-105. Tada, T., Watanabe, Y., Matsuoka, A., Ikeda-Saito, M., Imai, K., Ni-hei, Y.,Shikama, K., 1998. African elephant myoglobin with an unusual autoxidation behavior: comparison with the H64Q mutant of sperm whale myoglobin. Biochim. Biophys. Acta. 1387:165-176. 